\title{
BIBLIOGRAFÍA DE ARTE MUDÉJAR. ADDENDA (1992-1995)
}

\author{
Ana Reyes Pacios Lozano
}

Las referencias bibliográficas sobre el Arte Mudéjar que aparecen a continuación constituyen una addenda a la Bibliografía de arquitectura y techumbres mudéjares (1857-1991), publicada por el Instituto de Estudios Turolenses en 1993. En este trabajo, y como es habitual en toda addenda, pretendemos completarla y mantenerla al día con nuevas aportaciones que se han producido a lo largo del período 1992-1995, además de añadir otras obras que en su momento no se incluyeron por delimitación temática, omisión o porque no se localizaron.

Continuamos la línea de la bibliografía ya referida en cuanto a metodología, estructura y materiales recogidos ${ }^{1}$. No obstante, respecto a las materias tratadas, hemos de indicar que, aunque seguimos centrándonos en la arquitectura y las techumbres, hemos incorporado algunos estudios que versan sobre las Artes Decorativas Mudéjares, dado su interés. De ahí que en la estructura de la bibliografía, dentro de los apartados dedicados a trabajos no referidos a un ámbito territorial determinado, hayamos sustituido el bloque temático titulado Decoración por el de Artes Decorativas ${ }^{2}$. A su vez, éste se subdivide en los siguientes más particulares: Cerámica, Encuadernación y Manuscritos, Orfebrería y Tejidos-Alfombras. En el caso de la cerámica debemos señalar que volvemos a ceñinos a los estudios centrados en la de aplicación arquitectónica, dada la ingente cantidad de bibliografía especializada sobre el tema. Aún así, creímos oportuno incluir algunos estudios sobre piezas exentas tradicionalmente consideradas como mudéjares y en los que se hace referencia a técnicas y decoración típicamente mudéjares.

Por razones de espacio y características del trabajo, ofrecemos la referencia bibliográfica de cada publicación, siguiendo la norma ISO-690-87 que

1. La explicación detallada de todos estos aspectos puede consultarse en Pacios LozANO, Ana Reyes, Bibliografía de arquitectura y techumbres mudéjares, 1857-1991, Teruel, Instituto de Estudios Turolenses, 1993, pp. 13-32. En cuanto a las fuentes secundarias que venimos utilizando para extraer referencias relativas al estilo en cuestión hemos de añadir: GIL GrIMAU, Rodolfo y ROLDÁN CASTRO, Fátima, Corpus aproximativo de una bibliografía española sobre AlAndalus (I), Sevilla, Alfar, 1993.

2. Pacios Lozano, Ana Reyes, op. cit., p. 6, punto 2.7. 
veníamos utilizando, prescindiendo de la información relativa a su contenido. De igual forma, y al no ir enumeradas las mismas, no aparecen referencias cruzadas ni índices, aunque algunos trabajos son susceptibles de encuadrarse en apartados temáticos distintos. En los que se daba esta circunstancia los ubicamos en aquellos epígrafes que se ajustaban más a su contenido.

Todas las publicaciones referenciadas son fuentes primarias, de ahí que no aparezca el apartado que en la bibliografía base dedicamos a las obras de referencia con la intención de facilitar a un posible investigador en la materia una primera toma de contacto con la misma.

Finalmente, indicar que las nuevas aportaciones que se han llevado a cabo sobre el tema son escasas aunque ininterrumpidas ${ }^{3}$. Tenemos constancia de algunos trabajos que se están realizando, así como de otros que se encuentran en prensa y de los que esperamos poder dar noticia en una nueva revisión de la bibliografía.

\section{ASPECTOS GENERALES SOBRE EL ARTE MUDÉJAR}

BARBE-COQUELIN DE LISLE, Geneviève. La rencontre entre la civilisation de l'Islam et la civilisation europeenne: art et societé mudéjars. En Recherche et pluridisciplinarité. Actes du Colloque de Gif-sur-Yvette, Avril 1979. Paris: Publications du Conseil Scientifique de la Sorbonne Nouvelle, Paris III, [s.a.], p. 33-35. (Separata)

HenARes CuÉlLAR, Ignacio. El mudéjar, síntesis de culturas. En El mudéjar iberoamericano: del Islam al Nuevo Mundo [Catálogo Exposición Palacio Episcopal, Málaga, 1 abril-15 julio 1995]. Granada: Proyecto Sur de Ediciones, 1995, p. 27-85.

MORALES, Alfredo J. El arte mudéjar como síntesis de culturas. En El mudéjar iberoamericano: del Islam al Nuevo Mundo. Barcelona: Lunwerg Editores, 1995, p. 59-65.

\section{TEORÍA SOBRE EL ESTILO, INTERPRETACIÓN Y TERMINOLOGÍA}

Borrás Gualis, Gonzalo. El arte mudéjar: estado actual de la cuestión. En Aguilar, María Dolores et al. Mudéjar Iberoamericano: Una expresión cultural de dos mundos. I. Henares y R. López Guzmán (eds.). Granada: Servicio de Publicaciones de la Universidad de Granada, 1993, p. 9-19.

COMEz Ramos, Rafael. Una aproximación al arte mudéjar. Anales del Instituto de Investigaciones Estéticas, 1983, nº 53, p. 41-48.

HeNARES CUÉllaR, Ignacio. Perspectiva historiográfica finisecular del mudéjar en la península, archipiélagos atlánticos e iberoamérica. En El mudéjar iberoamericano: del Islam al Nuevo Mundo. Barcelona: Lunwerg Editores, 1995, p. 17-33.

3. Al término de este trabajo, julio de 1995, todavía no fue posible consultar las principales revistas especializadas en arte en sus números correspondientes a este año, e incluso algunas de 1994, por lo cual es probable que haya que incorporar algún nuevo estudio sobre el tema a nuestra bibliografía. 


\section{CRÍTICA A LOS TRATADOS}

NUERE [MATAUCO], Enrique. La carpintería en España y América a través de los tratados. Aguilar, María Dolores et al. Mudéjar Iberoamericano: Una expresión cultural de dos mundos. I. Henares y R. López Guzmán (eds.). Granada: Servicio de Publicaciones de la Universidad de Granada, 1993, p. 173-187.

\section{ARQUITECTURA}

BARBE [COQUelin DE LISLe], Geneviève. La tradition mudéjare en Espagne. En La Maison de Ville a la Renaisance: Recherches sur l'habitat urbain en Europe aux XVe. et XVIe. siècles. Actes du colloque tenu à Tours du 10 au 14 mai 1977. Paris: Picard, 1983, p. 85-88.

\section{TECHUMBRES}

Mudejar Wood-Carvings in the Collection of the Hispanic Society of America. New York: The Hispanic Society of America, 1928, 63 p.

Nuere Matauco, Enrique. La técnica de la carpintería de lo blanco en España y América. En Formación Profesional y Artes Decorativas en Andalucía y América [IV Seminario de Arquitectura Andalucía/América, 28-30 noviembre 1990]. Sevilla: Junta de Andalucía, Consejería Cultura y Medio Ambiente, 1991, p. 47-55.

Distribución de techumbres de madera en España. En Actas IV Simposio Internacional de Mudejarismo: Economía, Teruel, 17-19 septiembre, 1987. Teruel: Instituto de Estudios Turolenses de la Excma. Diputación Provincial, 1992, p. 79-88.

\section{ARTES DeCORATIVAS}

\section{CERÁMTCA}

Aguado Villalba, José. Tinajas medievales españolas: Islámicas y Mudéjares. Toledo: Instituto de Investigaciones y Estudios Toledanos de la Diputación Provincial, D.L. 1991, 231 p. ISBN 84-87103-11-1.

Martín Gómez, Carmen. Una forma cerámica mudéjar: anafes. En Actas II Simposio Internacional de Mudejarismo: Arte, Teruel, 19-21 noviembre, 1981. Teruel: Instituto de Estudios Turolenses de la Excma. Diputación Provincial de Teruel (CSIC), 1982, p. 87-91.

VAN DE PUT, A. Hispano-moresque ware of the XV century: A contribution to its history and chronology based upon armorial specimens. London and Tonbridge: Bradbury, Agnew \& C.O., L.D., printers, 1904, 105 p.

\section{ENCUADERNACIÓN Y MANUSCRITOS}

LóPEZ SERRANO, Matilde. La encuadernación artística. Goya, julio-diciembre 1986, ${ }^{\text {os }}$ 193-195, p. 14-21. 
MÉndeZ APARICIO, Julia. Las encuadernaciones de los siglos XV, XVI, y XVII de la biblioteca pública de Toledo. Toletum, 1971-74, Año XLVIII, nº 7, p. 27-49.

SPAlding, Frances. Mudejar Ornament in Manuscripts. New York: The Hispanic Society of America, 1953, VI + 58 p.

ZAID, Rhona. The muslim/mudejar in the Cantigas of Alfonso X, el Sabio. Sharq alAndalus, 1987, n 4, p. 145-152.

\section{ORFEBRERÍA}

ESTEBAN LORENTE, Juan F. Huellas mudéjares en la platería española del gótico y renacimiento. En Actas I Simposio Internacional de Mudejarismo, Teruel, 15-17 septiembre, 1975. Madrid; Teruel: Consejo Superior de Investigaciones Científicas; Diputación Provincial de Teruel, 1981, p. 151-153.

\section{TEIIDOS-ALFOMBRAS}

FERRANDIS TORRES, J. Alfombras hispano-moriscas "tipo Holbein". Archivo Español de Arte, $1942, \mathrm{n}^{\circ} 49$, p. 103-111.

NiÑo Y MÁs, Felipa. Tela hispano-morisca y bordados marroquíes. Nota descriptiva. En Adquisiciones [del Museo Arqueológico Nacional] en los años 1930 y 1931, siendo directores generales de Bellas Artes don Manuel Gómez-Moreno y don Ricardo de Orueta, y director del museo don Francisco Alvarez-Ossorio. Madrid: Museo Arqueológico Nacional, 1932, 5 p.

\section{FOCOS MUDÉJARES REGIONALES}

\section{ANDALUCÍA}

BANDA $Y$ VARGAS, Antonio de la. Las órdenes militares en la Baja Andalucía. En Actas del Simposio "El arte y las órdenes militares", Cáceres, 26-27 abril, 1985. Cáceres: Comité Español de Historia del Arte; Departamento de Historia del Arte de la Universidad de Extremadura, 1985, p. 33-37.

CAMPs CAZORla, Emilio. Puertas mudéjares con inscripción eucarística. Archivo Español de Arte y Arqueología, 1927, t. III, p. 197-220.

Domínguez Perela, Enrique. El brocal hispano-musulmán del Museo Lázaro Galdiano. Goya, enero-febrero 1985, n 184 , p. 210-214.

Hernández NúÑEZ, Juan Carlos y Martínez Montiel, Luis Francisco. Arquitectura mudéjar en Andalucía Occidental. En El mudéjar iberoamericano: del Islam al Nuevo Mundo. Barcelona: Lunwerg Editores, 1995, p. 169-177.

LÓPEZ GUZMÁN, Rafael. La carpintería de lo blanco en el mudéjar andaluz y americano. En Formación Profesional y Artes Decorativas en Andalucía y América [IV Seminario de Arquitectura Andalucía/América, 28-30 noviembre 1990]. Sevilla: Junta de Andalucía, Consejería Cultura y Medio Ambiente, 1991, p. 57-71.

MÉndez CASAl, Antonio. Los viejos artesonados españoles. Blanco y Negro, 31 octubre $1926, \mathrm{n}^{\circ} 1850$, s.p. 
Nuere Matauco, Enrique. La carpintería hispanomusulmana en el Renacimiento Andaluz. En La arquitectura del Renacimiento en Andalucía: Andrés de Vandelvira y su época. Exposición, 2 octubre-30 noviembre 1992. [Sevilla]: Junta de Andalucía, 1992, p. 151-167.

SANZ, María Jesús. El mudejarismo y su pervivencia en las artes suntuarias de Andalucia Occidental. En V Congreso Español de Historia del Arte, 29 octubre-3 noviembre 1984. Barcelona: Generalitat Catalunya, Departament de Cultura, D.L. 1987, vol. I, p. 281-288.

\section{ALMERÍA}

AguILAR GARCíA, María Dolores. El mudéjar en el Reino de Granada: realizaciones de Almería y Málaga. En AgulLaR, María Dolores et al. Mudéjar Iberoamericano: Una expresión cultural de dos mundos. I. Henares y R. López Guzmán (eds.). Granada: Servicio de Publicaciones de la Universidad de Granada, 1993, p. 55-77.

FONTENLA BALLESTA, Salvador. Almirez hispanomorisco procedente de Inox (Almería). Boletín de la Asociación Española de Orientalistas, 1994, Año XXX, p. 299-300.

\section{CÁDIZ}

Aguilar García, María Dolores. Aportaciones a la obra de Pedro Díaz de Palacios (+1636): La iglesia parroquial de Ubrique (Cádiz). Boletín del Museo Diocesano de Arte Sacro, enero-diciembre 1981, 1-2, p. 15-32.

\section{GRANADA}

Capel Margarito, Manuel. Aspectos económicos del arte mudéjar en Granada. En Actas IV Simposio Internacional de Mudejarismo: Economía, Teruel, 17-19 septiembre, 1987. Teruel: Instituto de Estudios Turolenses de la Excma: Diputación Provincial, 1992, p. 535-548.

CAPel Margarito, Manuel y MARTín PAIDAl, Francisco. Inventario artístico del municipio de Lecrín. Cuadernos de Arte de la Universidad de Granada, 1992, nº XXIII, p. 633-646.

GÓmez-MORENo CaLera, José Manuel. Las iglesias del Valle de Lecrín, arte e historia. El Valle, abril 1989, $\mathrm{n}^{\circ} 19-23$, p. 3-5.

- El arquitecto granadino Ambrosio de Vico. Granada: Universidad de Granada, Servicio de Publicaciones, 1992. 3.1.3. Iglesias mudéjares, p. 78-91.

- El arte granadino en el siglo XVI: el desfase centro-periferia. En Actas VIII Congreso Nacional de Historia del Arte, I, Cáceres, 3-6 octubre 1990. Mérida: Editora Regional de Extremadura, 1992, p. 239-242.

- Juan de Maeda a la sombra de Siloé. Noticias y reflexiones sobre su vida y obra. Cuadernos de Arte de la Universidad de Granada, 1992, n XXIII, p. 137-158.

- Un nuevo proyecto de Siloé: la iglesia de Santiago de Guadix. Cuadernos de Arte de la Universidad de Granada, 1993, n XXIV, p. 21-39.

- El mudéjar granadino. En El mudéjar iberoamericano: del Islam al Nuevo Mundo. Barcelona: Lunwerg Editores, 1995, p. 143-155. 
GómeZ-Moreno [MARTíneZ], Manuel. Arte cristiano entre los moros de Granada. En Homenaje a D. Francisco Codera en su jubilación del profesorado. Zaragoza: Mariano Escar, Tipógrafo, 1904, p. 259-270.

HENARES CuÉllar, Ignacio. La arquitectura mudéjar después de la conquista de Granada. Un modelo de organización espacial, productiva y simbólica. En Aguilar, María Dolores et al. Mudéjar Iberoamericano: Una expresión cultural de dos mundos. I. Henares y R. López Guzmán (eds.). Granada: Servicio de Publicaciones de la Universidad de Granada, 1993, p. 21-37.

- Las puertas talladas de la Alhambra. La Esfera, 9 junio 1928, n 753, p. 10.

VALLADAR, Francisco de Paula. Las artes suntuarias en Granada. Construcciones mudéjares. Revista de España, 1890, t. CXXVII, p. 70-100.

VELASCO GÓMEZ, José María. Estructura original de elementos lígneos en el patio de los leones. Cuadernos de la Alhambra, 1992, vol. 28, p. 199-229.

\section{HuELVA}

AMADOR DE LOS Ríos, Rodrigo. De Arte Mahometano. Las murallas de Niebla (notas de viaje). Revista de Archivos, Bibliotecas y Museos, julio-diciembre 1906, t. XV.2, $\mathrm{n}^{\text {os }} 9$ y 10, p. 212-232.

Marín Fidalgo, Ana. Arquitectura gótica del sur de la provincia de Huelva. Huelva: Excma. Diputación Provincial de Huelva, Instituto de Estudios Onubenses "Padre Marchena", 1982. 4. Análisis de Tecnologías y Formas Arquitectónicas, D. Artesonados, p. 105-106.

\section{JAÉN}

AMADOR DE lOS Ríos, Rodrigo. Monumentos de la ciudad de Jaén. Revista de Archivos, Bibliotecas y Museos, marzo-abril 1905, t. XII, ${ }^{\text {os }} 3$ y 4, p. 173-194.

Escolano Gómez, Francisco. La iglesia de San Andrés de Baeza. Cuadernos de Arte de la Universidad [Granada], 1942-1944, vol. VII-IX, p. 7-17.

Gila MedinA, Lázaro. El mudéjar en Jaén. Aproximación a una fecunda realidad artística. En El mudéjar iberoamericano: del Islam al Nuevo Mundo. Barcelona: Lunwerg Editores, 1995, p. 127-141.

LÁzARO DAMAS, Soledad. La iglesia del Convento de Santa Clara de Jaén. Revista Senda de los Huertos, 1986, n 3, p. 29-36.

MarTos, Ramón. Techumbre mudéjar de la iglesia de Santo Domingo. Revista Paisaje, $1947, \mathrm{n}^{\circ} 32$, p. 869-870.

Ruiz Povedano, José María. La iglesia parroquial de Santa María (Alcaudete, Jaén). La transición del gótico-mudéjar al renacimiento. Cuadernos de Historia Medieval, 1979, t. IV-V, p. 291-305.

Galera Andreu, P.A. Gótico mudéjar. En Historia de Jaén. Jaén: Diputación Provincial, Colegio Universitario de Jaén, 1982, p. 590-593.

\section{MÁlaga}

Aguilar García, María Dolores. Arte mudéjar en Málaga: aspectos económicos. En Actas IV Simposio Internacional de Mudejarismo: Economía, Teruel, 17-19 septiem- 
bre 1987. Teruel: Instituto de Estudios Turolenses de la Excma. Diputación Provincial, 1992, p. 507-519.

- El mudéjar en el reino de Granada: Realizaciones de Almería y Málaga. En El mudéjar iberoamericano: del Islam al Nuevo Mundo. Barcelona: Lunwerg Editores, 1995, p. 157-167.

Suberbiola Martínez, Jesús. La construcción de la iglesia mudéjar de Comares y otras de su aca (1532-1552). Boletín de Arte, 1992-1993, n ${ }^{\text {ss }} 13-14$, p. 61-89.

\section{SEVILLA}

AMADOR De los Ríos, José. Puertas del Salón de Embajadores del Alcázar de Sevilla. Museo Español de Antigüedades, 1874, t. III, p. 433-470.

AMADOR DE los Ríos Y Villalta, Rodrigo. Hoja de puerta mudéjar conservada en la sacristía alta de la catedral de Sevilla. Museo Español de Antigüiedades, 1878, t. IX, p. 400-420.

ARCEnEgui y CARmona, I. Marchena: iglesia de San Juan. Reales Sitios, 1976, 13 (supl.), p. 225-232.

Cano Navas, María Luisa. El convento de San José del Carmen de Sevilla: Estudio histórico-artístico. Sevilla: Secretaría de Publicaciones de la Universidad de Sevilla, 1984, 322 p. ISBN 84-7405-278.

COMEz RAmos, Rafael. La iglesia de Santa Marina de Sevilla. Sevilla: Diputación Provincial, 1993, 82 p.+ lam. ISBN 84-7798-096-9.

Duclos BAUTISTA, Guillermo. Carpintería de lo blanco en la arquitectura religiosa de Sevilla. Sevilla: Diputación Provincial de Sevilla, 1992, 357 p. ISBN 84-7798-088-8.

FRAGA IRIBARNE, María Luisa. Conventos femeninos desaparecidos: Arquitectura religiosa perdida durante el siglo XIX en Sevilla. Sevilla: Ediciones Guadalquivir, 1993, 253 p. ISBN 84-86080-67-3.

MORALES, Alfredo J. Reflexiones sobre algunas iglesias mudéjares del Aljarafe sevillano. En AguILAR, María Dolores et al. Mudéjar Iberoamericano: Una expresión cultural de dos mundos. I. Henares y R. López Guzmán (eds.). Granada: Servicio de Publicaciones de la Universidad de Granada, 1993, p. 39-54.

Olva Alonso, Diego. Aproximación a la cerámica mudéjar sevillana y sus relaciones con otros centros alfareros contemporáneos. En Actas del II Simposio Internacional de Mudejarismo: Arte, Teruel, 19-21 noviembre, 1981. Teruel: Instituto de Estudios Turolenses de la Excma. Diputación Provincial de Teruel (CSIC), 1982, p. 81-85.

SierRa Fernández, Juan Alonso de la y LASSO de la VEGA PORRES, María de Gracia. Tinajas mudéjares del Museo Arqueológico de Sevilla: Tipología y decoración. En Homenaje a Conchita Fernández Chicarro. Madrid, 1982, p. 457-470.

\section{ARAGÓN}

Alvaro Zamora, María Isabel. Pervivencias técnicas y ornamentales de la cerámica medieval mudéjar en la alfarería aragonesa posterior al 1610. En Segundo Coloquio Internacional de Cerámica Medieval en el Mediterráneo Occidental, Toledo 
1981. Madrid: Ministerio de Cultura, Dirección General de Bellas Artes, 1986, p. $433-439$.

- Tradición e innovación en la cerámica aragonesa. En Las artes en Aragón durante el reinado de Fernando el Católico. Zaragoza: Institución Fernando el Católico, Diputación de Zaragoza, 1993, p. 199-222.

BorRás GuALIS, Gonzalo M. El arte mudéjar. En Pabellón de Aragón/ Pavilion of Aragón. Exposición Universal Sevilla 1992. [s.l.]: Pabellón de Aragón, 1992, p. 117-125.

- Arte Mudéjar en Aragón. En Aguilar, María Dolores et al. Mudéjar Iberoamericano: Una expresión cultural de dos mundos. I. Henares y R. López Guzmán (eds.). Granada: Servicio de Publicaciones de la Universidad de Granada, 1993, p. 125-143.

- Arte Mudéjar Aragonés. En El mudéjar iberoamericano: del Islam al Nuevo Mundo. Barcelona: Lunwerg Editores, 1995, p. 77-89.

Olivar DAYDI, M. La cerámica trecentista en los países de la corona de Aragón. Barcelona: Seix Barral, [1952], 153 p. +124 h.

RinCón GARCíA, Wifredo. El mudéjar y la Orden del Santo Sepulcro en Aragón. En Actas del Simposio "El arte y las órdenes militares", Cáceres, 26-27 abril, 1985. Cáceres: Comité Español de Historia del Arte; Departamento de Historia del Arte de la Universidad de Extremadura, 1985, p. 247-254.

\section{HUESCA}

Conte CazCarro, Anchel. Los restos mudéjares de la iglesia de Robres. El Pimendón, marzo-abril 1992 (suplemento), 8 p.

\section{TERUEL}

BARBE-COQUelin DE LISLE, Geneviève. La campagne et la ville dans le plafond de la cathédrale de Teruel. En Mélanges offerts à Maurice Molho. Paris: Editions Hispaniques, 1988, vol. I, p. 27-37.

López Gómez, José Manuel. El mudéjar de Teruel. En Pabellón de Aragón / Pavilion of Aragón. Exposición Universal Sevilla 1992. [s.l.]: Pabellón de Aragón, 1992, p. 139-149.

\section{ZARAGOZA}

Alvaro ZAMORA, María Isabel. La torre de Santa María de Utebo y la azulejería de Muel. "M. A. Z." Mutua de Accidentes de Zaragoza, 1978, 69, p. 25-27.

- La cerámica de Muel. [Zaragoza]: Diputación de Zaragoza, Servicio de Cultura, 1989, [34 p.]

- El Museo Etnológico de Muel. Interés de sus fondos de azulejería. Artigrama, 1991-1992, n $^{\text {os }} 8-9$, p. 165-198.

ANTOLín COMA, Carmen. Sobre las condiciones establecidas en los contratos de fustería en Zaragoza a principios del siglo XVI. En Actas IV Simposio Internacional de Mudejarismo: Economía, Teruel, 17-19 septiembre, 1987. Teruel: Instituto de Estudios Turolenses de la Excma. Diputación Provincial, 1992, p. 187-192. 
BARBE-COQUELIN DE LISLE, Geneviève. L'architecture mudejar entre la chrétienté et 1'Islam: les églises aragonaises de Tobed, Torralba de Ribota, Maluenda et Cervera de la Cañada (1356-1426). Cahiers de l'UFR d'études ibériques et latinoaméricaines, 5 [Actes du colloque organisé à la Sorbonne par le GRIMES REP, 2325 janvier, 1986], p. 23-30.

BRUÑÉn IbÁÑEz, Ana Isabel y SENAC Rubio, María Begoña. Noticia sobre la capilla de Nuestra Señora del Carmen en la iglesia parroquial de Brea de Aragón (Zaragoza). En I Encuentro de Estudios Bilbilitanos, Calatayud, 18-20 noviembre 1982. Calatayud: Centro Estudios Bilbilitanos de la Institución "Fernando el Católico", 1982, I, p. 163-166.

BRuñÉn IbÁÑEz, Ana Isabel; CALvo Comín, María Luisa y SENAC Rubio, María Begoña. El arquitecto Juan de Marca y su actividad en la Comunidad de Calatayud, siglo XVII. En Actas II Encuentro de Estudios Bilbilitanos, Calatayud, 5-7 diciembre, 1986. Zaragoza: Centro de Estudios Bibilitanos, Fundación "Institución Fernando el Católico", 1989, I, p. 381-385.

CABAÑERo SuBizA, Bernabé. Nuevos datos sobre la evolución de la decoración vegetal de la época de taifas a la almorávide a la luz de un capitel mudéjar del monasterio de Rueda (Zaragoza). Artigrama, 1991-1992, nos 8-9, p. 281-288.

CAMPILlo, Toribio del. Apuntes acerca de una puerta procedente de Daroca, en el Museo Arqueológico Nacional. Museo Español de Antigüedades, 1873, t. II, p. 413-428.

ESCRIBANO SÁNCHEZ, José C. Notas sobre un taller de taracea en Torrellas (Zaragoza) er el siglo XVI. En Actas II Simposio Internacional de Mudejarismo: Arte, Teruel, 19-21 noviembre, 1981. Teruel: Instituto de Estudios Turolenses de la Excma. Diputación Provincial (CSIC), 1982, p. 247- 249.

Establés ElduQue, José María. Planimetría del mudéjar Calatayubí. En Actas II Encuentro de Estudios Bilbilitanos, Calatayud, 5-7 diciembre, 1986. Calatayud: Centro de Estudios Bibilitanos, Fundación "Institución Fernando el Católico", 1989, I, p. 199-219.

EXPóstTo SEBASTiÁN, Manuel. Reflexiones en torno a la Aljafería y el arte mudéjar. En Pabellón de Aragón / Pavilion of Aragon. Exposición Universal Sevilla 1992. [s.1.]: Pabellón de Aragón, 1992, p. 125-139.

Galindo y RoMeo, Pascual. Un mueble cristiano mudéjar: el facistol del Papa Luna. En Memorias de la Facultad de Filosofia y Letras. Zaragoza: Universidad de Zaragoza, 1922-23, t. I, p. 371-378.

GARCía MARCO, Francisco Javier. Espacio urbano y rural en las aljamas mudéjares de las cuencas del Jalón y el Jiloca Medios. En Simposio Internacional sobre la ciudad islámica, Zaragoza, 1-4 diciembre, 1988. Ponencias y comunicaciones. Zaragoza: Institución Fernando el Católico, 1991, p. 411-430.

GÓMEZ URDÁÑ̈EZ, Carmen. Los moriscos zaragozanos en los oficios de la construcción. Circunstancias laborales y económicas. En Actas IV Simposio Internacional de Mudejarismo: Economía, Teruel, 17-19 septiembre, 1987. Teruel: Instituto de Estudios Turolenses de la Excma. Diputación Provincial, 1992, p. 651-665.

LOMBA SERRANO, Concepción. La casa de la Estanca (Borja). Una muestra de arquitectura civil mudéjar aragonesa. Cuadernos de Estudios Borjanos, octubre 1978, II, p. 93-108. 
MAÑAs BALlestín, Fabián. El retablo relicario del monasterio de Piedra. En Actas II Encuentro de Estudios Bilbilitanos, Calatayud, 5-7 diciembre, 1986. Calatayud: Centro de Estudios Bibilitanos, Fundación "Institución Fernando el Católico", 1989, I, p. 323-352.

SANMiguel MATEO, Agustín. Alminares de la Marca Superior. Sharq al-Andalus, 1992, $\mathrm{n}^{\circ}$ 9, p. 195-222.

Usón SARDAÑA, Celia y DUCAR Esteban, María Inés. Un alfarje mudéjar en la iglesia de la Virgen de Tobed. Seminario de Arte Aragonés, 1988-89, 42-43, p. 5-46.

\section{CANARIAS}

FRAGA GONZÁLEZ, Carmen. Arquitectura religiosa de los siglos XVII y XVIII. En Historia del Arte en Canarias. Las Palmas de Gran Canaria: EDIRCA, 1982, p. 110-112.

- Carpintería mudéjar en los archipiélagos atlánticos Canarias, Madeira y Azores. En AgulLAR, María Dolores et al. Mudéjar Iberoamericano: Una expresión cultural de dos mundos. I. Henares y R. López Guzmán (eds.). Granada: Servicio de Publicaciones de la Universidad de Granada, 1993, p. 157-171.

- Diccionario de ensambladores y carpinteros de lo blanco (siglos XVI y XVII). Anuario de Estudios Atlánticos, 1993, n³9, p. 185-289.

- Aspectos de la arquitectura mudéjar en Canarias. $2^{\text {a }}$ ed. [Madrid]: Ediciones del Cabildo Insular de Gran Canaria, 1994, 103 p. ISBN 84-8103-054-6.

- Fragueiros y carpinteros portugueses en la arquitectura canaria. En Homenaje a José Pérez Vidal. Tenerife: Universidad de la Laguna, 1993, p. 459-471.

- Los Archipiélagos Atlánticos. En El mudéjar iberoamericano: del Islam al Nuevo Mundo. Barcelona: Lunwerg Editores, 1995, p. 191-198.

LozoyA, Marqués de. La huella portuguesa en el Arte de las islas Canarias. Coloquio (Lisboa), febrero $1970, n^{\circ} 57$, p. 3-10.

Martínez de la PeÑa y GonzÁlez, Domingo. El alfiz en la arquitectura canaria. En Homenaje a Elias Serra Ráfols. Las Palmas de Gran Canaria: Universidad de La Laguna, 1970, t. II p. 407-415.

\section{LAS PALMAS}

Alzola, José Miguel. La iglesia de San Francisco de Asís de Las Palmas. Las Palmas de Gran Canaria: Real Sociedad Económica de Amigos del País-Fundación Mutua Guanarteme, 1986. Cap. VI. La reconstrucción, p. 33-61.

\section{SANTA CRUZ DE TENERIFE}

Rodríguez, Gloria. Iglesia de El Salvador de Santa Cruz de la Palma. [s.1.]: Excmo. Cabildo Insular de La Palma, 1985. III. Aspectos artísticos de El Salvador. 1. Arquitectura. 1) Elementos mudéjares, p. 115-120.

\section{EXTREMADURA}

Mogollón CANO-CORTÉs, Pilar. El mudéjar en Extremadura. En El mudéjar iberoamericano: del Islam al Nuevo Mundo. Barcelona: Lunwerg Editores, 1995, p. 99-109. 


\section{BADAJOZ}

Mogollón CANO-Cortés, Pilar. El monasterio de Tentudía, Vicaría de la Orden Militar de Santiago. En Actas del Simposio "El arte y las órdenes militares", Cáceres, 26-27 abril, 1985. Cáceres: Comité Español de Historia del Arte; Departamento de Historia del Arte de la Universidad de Extremadura, 1985, p. 169-186.

PeÑa Gómez, María del Pilar. Aproximación tipológica de la plaza mayor de Llerena. Norba-Arte, 1985, VI, p. 85-107.

- La torre de la iglesia de Nuestra Señora de la Granada de Llerena (Badajoz). En Actas del Simposio "El arte y las órdenes militares", Cáceres, 26-27 abril, 1985. Cáceres: Comité Español de Historia del Arte; Departamento de Historia del Arte de la Universidad de Extremadura, 1985, p. 227-235.

RuIZ MATEOS, Aurora. Residencias del Tribunal de la Inquisición de Llerena en palacios santiaguistas. En Actas del Simposio "El arte y las órdenes militares", Cáceres, 26-27 abril, 1985. Cáceres: Comité Español de Historia del Arte; Departamento de Historia del Arte de la Universidad de Extremadura, 1985, p. 255-273.

\section{CÁCERES}

García DuQue, María Isabel. Arquitectura civil gótica y renacentista en Cáceres. Revista de Estudios Extremeños, 1976, t. XXXII, nº I, p. 313-361.

VALVERDE Luengo, Francisco de Jesús. Descripción del templo parroquial de la Asunción de Galisteo. En Actas del VI Congreso de Estudios Extremeños, Trujillo, Mérida y Badajoz, mayo 1979. Cáceres; Badajoz: Institución Cultural "El Brocense"; Institución Cultural "Pedro de Valencia", 1981, t. I, p. 311-315.

\section{LA RIOJA}

SÁnchez Trujillano, María Teresa. Cerámica hispano-musulmana y mudéjar de Nájera. En II Congreso Arqueología Medieval Española, Madrid, 19-24 enero, 1987. Madrid: Comunidad de Madrid, Consejería de Cultura, Dirección General de Patrimonio Cultural, 1987, t. III, p. 158-165.

- Decoración mudéjar del Alcázar de Nájera. En II Jornadas de Historia Medieval. Nájera, 1991. Logroño: Instituto de Estudios Riojanos, 1992, p. 205-220.

- Restos mudéjares de la catedral de Santo Domingo de la Calzada: el alfarje de la sala capitular. En III Semana de Estudios Medievales, Nájera, 3-7 agosto 1992 Logroño: Instituto de Estudios Riojanos, 1993, p. 257-265.

\section{LEÓN Y CASTILLA LA VIEJA}

BANGO TORviso, Isidro G. El arte de construir en ladrillo en Castilla y León durante la Alta Edad Media, un mudéjar inventado en el siglo XIX. En AGUILAR, María Dolores et al. Mudéjar Iberoamericano: Una expresión cultural de dos mundos. I. Henares y R. López Guzmán (eds.). Granada: Servicio de Publicaciones de la Universidad de Granada, 1993, p. 109-123. 
LaVado Paradinas, Pedro José. Púlpitos mudéjares de yeso. Revista del Instituto Egipcio de Estudios Islámicos en Madrid, 1979-80, vol. XX, p. 145-171.

- La ciudad mudéjar: espacios y nuevas funciones. En Simposio internacional sobre la ciudad islámica, Zaragoza, 1-4 diciembre, 1988. Ponencias y Comunicaciones. Zaragoza: Institución Fernando el Católico, 1991, p. 431-446.

- Arquitectura doméstica en los conventos de monjas de Castilla y León. En I Congreso Internacional del Monacato Femenino en España, Portugal y América 14921992. León: Universidad de León, Secretariado de Publicaciones, D.L. 1993, t. II, p. 387-434.

- La huella musulmana en Castilla y Léon. En Proyección Histórica de España en sus tres culturas: Castilla y León, América y el Mediterráneo. Valladolid: Junta de Castilla y León, Consejería de Cultura y Turismo, 1993, t. II, p. 409-436.

- Palacios o conventos: arquitectura en los monasterios de Clarisas de Castilla y León. Verdad y Vida, 1994, t. LII, ${ }^{\text {os }}$ 207-208, p. 715-752.

NUERE MATAUCO, Enrique. La carpintería de armar castellana. Su influjo islámico y exportación al nuevo mundo. En El mudéjar iberoamericano: del Islam al Nuevo Mundo. Barcelona: Lunwerg Editores, 1995, p. 51-58.

Pérez Higuera, María Teresa. Arquitectura mudéjar en Castilla y Léon. [Valladolid]: Junta de Castilla y Léon, Consejería de Cultura y Turismo, 1993, 142 p. ISBN 847846-207-4.

- Arquitectura mudéjar en los antiguos reinos de Castilla y León. En El mudéjar iberoamericano: del Islam al Nuevo Mundo. Barcelona: Lunwerg Editores, 1995, p. $67-75$.

VALDÉS FERNÁNDEZ, Manuel. Arquitectura mudéjar y repoblación. Bases para una hipótesis. En Homenaje al profesor Hernández Perera. Madrid: Universidad Complutense de Madrid, Facultad de Geografía e Historia, Departamento de Historia del Arte II (Moderno); Comunidad Autónoma de Canarias, Dirección General de Patrimonio Histórico, 1992, p. 207-213.

TORRES BALBÁs, Leopoldo. Sillerías de coro mudéjares. Al-Andalus, 1954, vol. XIX, fasc. 1, p. 203-218.

\section{ÁvILA}

CERVERA VERA, Luis. Arévalo (Avila): Desarrollo urbano y monumental hasta mediados del siglo XVI. Madrid: Editorial Alpuerto, 1992, 399 p. ISBN 84-381-0168-2.

FERNÁNDEZ-SHAW TODA, María. Carpintería de lo blanco en la provincia de Avila (arquitectura religiosa). 2 vols. Tesis Doctoral inédita. Madrid, Universidad Complutense, junio 1994.

- Sotocoros y frentes de coro de madera en la provincia de Avila. Anales de la Historia del Arte, 1994, n 4 [Homenaje al profesor Dr. D. José María de Azcárate], p. 385-391.

Guerra, Ricardo et al. Arévalo y su tierra a la luz de ahora, con mirada de siglos. Avila: Autores, 1993, 216 p. ISBN 84-86009-07-3.

Muguruza Otaño, Pedro. El palacio de Don Juan II en Madrigal de las Altas Torres. Revista Nacional de Arquitectura, julio 1949, nº 91, p. 283-291. 
SÁnchez TrujIllano, María Teresa. La sillería mudéjar de San Nicolás de Madrigal de las Altas Torres. Cuadernos de la Alhambra, 1979-1981, 15-17, p. 249-253.

TAPIA, Serafín de. Personalidad étnica y trabajo artístico. Los mudéjares abulenses y su relación con las actividades de la construcción en el siglo XV. En Medievalismo y neomedievalismo en la arquitectura española: Aspectos generales. Actas del $1^{\mathrm{er}}$. Congreso, Avila, septiembre 1987. Pedro Navascués Palacio y José Luis Gutiérrez Robledo (eds.). Avila: Universidad de Salamanca; UNED-Avila (Fundación Cultural Santa Teresa), 1990, p. 245-252.

\section{BURGOS}

Huidobro Serna, Luciano. Los moros de Burgos y su influencia en el arte. Boletín de la Institución "Fernán González", 1948, no 105, p. 222-225.

Rico Santamaría, Marcos. Real Monasterio de las Huelgas de Burgos. Un somero análisis de sus arquitecturas. Academia: Boletín de la Real Academia de San Fernando, $2^{\circ}$ semestre 1991, $\mathrm{n}^{\circ} 73$, p. 89-101.

Rojo AceñA, Juan Carlos. Techumbre de la iglesia de San Nicolás en el barrio de Sinovas. Biblioteca: Estudio e Investigación, 1988, 3, p. 39-48.

\section{LEÓN}

BEVAN, Bernard. Early Mudéjar woodwork. Burlington Magazine, diciembre 1930, vol. LVII, $\mathrm{n}^{\circ}$ CCCXXXIII, p. 271-278.

CAMPOS SÁNChEZ-BORDONA, María Dolores. El hospital de Nuestra Señora la Blanca del Puente de Villarente y la arquitectura asistencial en el siglo XVI en León. Tierras de León, junio-septiembre 1990, t. 30, nº 79-80, p. 55-82.

FERNÁNDEZ BAIZÁN, María Luz. San Lorenzo de Sahagún: un ejemplo de arquitectura mudéjar en tierras de León. Madrid: Universidad Politécnica, 1992, 13 h. ISBN 8486189-30-6.

ViÑayo GonZÁlez, Manuel. Iglesia de Santa Colomba de la Vega. Archivos Leoneses, julio-diciembre 1962, Año XVI, nº 32, p. 301-304.

\section{PALENCIA}

CAmps Cazorla, Emilio. Sillas del coro de Santa Clara, de Astudillo. Nota descriptiva. En Adquisiciones [del Museo Arqueológico Nacional] en los años 1930 y 1931, siendo directores generales de Bellas Artes don Manuel Gómez-Moreno y don Ricardo de Orueta, y director del museo don Francisco Alvarez-Ossorio. Madrid: Museo Arqueológico Nacional, 1932, 8 p.

CASTRO GarCíA, Lázaro de. Tipos barbados medievales vistos por un artista mudéjar. Urgencias, 1975, nº 4, p. 156-158.

- Pinturas mudéjares desconocidas en Santoyo (Palencia). Minutos Menarini, $1976, \mathrm{n}^{\circ} 81$.

LAVADO PARADINAS, Pedro José y CASTRO, Lázaro de. Un mueble mudéjar en Saldaña (Palencia). Boletin de la Asociación Española de Orientalistas, 1976, Año XII, p. 219-227. 
Sancho Campo, Angel. Palencia Histórico Monumental. Palencia, 1975. Arte mudéjar, p. 56-57.

TOVAR, Antonio. Papeletas de arte mudéjar castellano. II. El púlpito de la ermita de Nuestra Señora del Castillo, en Amusco. Boletín del Seminario de Estudios de Arte y Arqueología, curso 1932-33, $2^{\circ}$ trimestre, fasc. II, p. 95-96.

\section{SALAMANCA}

CaAmaño Martínez, Jesús. El arte y las órdenes militares en la provincia de Salamanca. En Actas del Simposio "El arte y las órdenes militares", Cáceres, 26-27 abril, 1985. Cáceres: Comité Español de Historia del Arte; Departamento de Historia del Arte de la Universidad de Extremadura, 1985, p. 43-45.

NuERE MATAUCO, Enrique. Consideraciones sobre la supuesta economía de la carpintería mudéjar. En Actas IV Simposio Internacional de Mudejarismo: Economía, Teruel, 17-19 septiembre, 1987. Teruel: Instituto de Estudios Turolenses de Ia Excma. Diputación Provincial, 1992, p. 73-78.

\section{SEGOVIA}

DOTOR, Angel. España y el Islam. El castillo de Coca, gran arquetipo del arte morisco o mudéjar. Africa, septiembre 1971, p. 8-13.

NUERE, Enrique. Una hipótesis sobre la techumbre de San Millán de Segovia. Estudios Segovianos, 1992, t. XXXIII, nº 89, p. 289-309.

PITA ANDRADE, José Manuel. El castillo de Coca reconstruido. Goya, enero-febrero $1959, \mathrm{n}^{\circ} 28$, p. 210-216.

RUIz HeRnANDo, Antonio. La sinagoga de Ibáñez de Segovia, en Segovia. Estudios Segovianos, 1991, t. XXXII, nº 88, p. 139-158.

\section{VALLADOLID}

BALADO PACHÓN, Arturo et al. La maqbara de Valladolid: Un interesante cementerio mudéjar. Revista de Arqueología, noviembre 1991, n 127, p. 38-45.

BALAO GONZÁLEZ, Angel. Restauración de los baños árabes en el monasterio de Santa Clara. Reales Sitios, 1990, n 106, p. 49-54.

BujARRABAL, María Luisa y SANCHO, José Luis. El palacio mudéjar de Tordesillas. Reales Sitios, 1990, n 106, p. 29-36.

Herrero SANZ, María Jesús. La techumbre de la capilla mayor en la iglesia de Santa Clara de Tordesillas. Reales Sitios, 1991, t. 28, n¹07, p. 57-64.

ToAjas Roger, María Angeles. La techumbre del presbiterio de Santa Clara de Tordesillas. Análisis histórico-artístico y algunas conclusiones de su estudio. En Homenaje al profesor Hernández Perera. Madrid: Universidad Complutense de Madrid, Facultad de Geografía e Historia, Departamento de Historia del Arte II (Moderno); Comunidad Autónoma de Canarias, Dirección General de Patrimonio Histórico, 1992, p. 173-190. 


\section{ZAMORA}

CASAS y RuIz DEL ARBOL, F. Los templos de ladrillo. Salamanca: Imprenta de Núñez, 1947,104 p.

\section{LEVANTE}

AMADOR DE LOS Ríos, Rodrigo. Reliquias de los musulmanes en Cataluña. Revista de Archivos, Bibliotecas y Museos, septiembre-diciembre 1915, t. XXXIII, $\mathrm{n}^{\text {os }}$ 9-12, p. $173-212$.

GARÍN ORTíz DE TARANCO, Felipe María. Vinculaciones universales del gótico valenciano. Anales de la Universidad de Valencia, curso 1969-70, vol. XLIV, 78 p. (separata).

Martínez Caviró, Balbina. Temas figurados en las Lozas Doradas Levantinas. En La céramique médiévale en méditerranée occidentale X-XV siècles, Valbonne, 11-14 septiembre, 1978. Paris: Editions du Centre National de la Recherche Scientifique, 1980, p. 375-383.

Puig i Cadafalch, J. Els banys de Girona i la influencia moresca a Catalunya. Anuari de l'Institut d'Estudis Catalans, 1913-14, part. I, p. 687-728.

\section{Castellón}

Zaragoza CATALÁN, Arturo. La iglesia de Vallibona (Castellón) y las techumbres de iglesias de arcos y armaduras valencianas. Boletín de Amigos de Morella y su Comarca, 1990-91, p. 33-47.

\section{LÉRIDA}

Beltrán Roige, Prim. La cerámica decorada del gótic a Catalunya. En La ceramica medievale nel Mediterraneo Ocidentale. Congreso Internazionale della Universita degli Studi di Siena, Siena 8-12 ottobre, Fireze, 13 ottobre 1984. Fireze: Edizioni all'Insegna del Giglio, 1986, p. 227-233.

Giralt Balaguero, Josep. Alicatados del "Castell Formos" de Balaguer. En Segundo Coloquio Internacional de Cerámica Medieval en el Mediterráneo Occidental, Toledo, 1981. Madrid: Ministerio de Cultura, Dirección General de Bellas Artes, 1986, p. 429-432.

PitA Merce, Rodrigo. Lérida Morisca. Lérida: Dilagro, 1977. Cap. XII. Arqueología y arte de los moriscos leridanos, p. 155-163.

\section{Murcia}

AMORES LloRET, R. Cerámica vidriada con decoración estampillada de Lorca (Murcia). En Segundo Coloquio Internacional de Cerámica Medieval en el Mediterráneo Occidental, Toledo, 1981. Madrid: Ministerio de Cultura, Dirección General de Bellas Artes, 1986, p. 417-420.

\section{TARRAGONA}

COMPANYS [FARRERONS], Isabel y MONTARDIT [Bofarull], Núria. Embigats gòtics del palau reial de Santes Creus. Santes Creus, Tarragona: Arxiu Bibliogràfic de Santes Creus, 1982, 19 p. + il. 


\section{VALENCIA}

BARRACHINA, Jaime. Un "socarrat" paternero de tema zodiacal. En Segundo Coloquio Internacional de Cerámica Medieval en el Mediterráneo Occidental, Toledo, 1981. Madrid: Ministerio de Cultura, Dirección General de Bellas Artes, 1986, p. 415-416.

BERCHEZ, Joaquín y ZARAGOZA, Arturo. En torno al legado hispanomusulmán en el ámbito arquitectónico valenciano. En El mudéjar iberoamericano: del Islam al Nuevo Mundo. Barcelona: Lunwerg Editores, 1995, p. 91-97.

GARCía de VARGAS, Ricardo. Estudio sobre la iglesia antigua de Godella. Valencia, Burjasot: Ayuntamiento de Godella, 1956, 25 p.

Gestoso, Paz. Cerámica morisca. Revista de las Artes y los Oficios, febrero-marzo 1947, $n^{\circ}$ 33-34, p. 15-19.

LAVADo Paradinas, Pedro José. Los baños árabes y judíos en la España medieval. En EPALZA, Míkel et al. Baños árabes en el País Valenciano. Valencia: Generalitat Valenciana, Consellería de Cultura, Educació i Ciencia, D.L. 1989, p. 45-78.

Lerma, J.V.; MARTí, J.; PASCual, J.; SOler, M.P.; EscribÁ, F.; y Mesquida, M. Sistematización de la loza gótico-mudéjar de Paterna/Manises. En La ceramica medievale nel Mediterraneo Occidentale. Congreso Internazionale della Universitá degli Studi di Siena, Siena 8-12 ottobre, 1984, Fireze, 13 ottobre 1984. Fireze: Edizioni all'Insegna del Giglio, 1986, p. 227-233.

SARTHOU CARRERES, Carlos. El museo de Játiva. Datos histórico-descriptivos. Valencia Atracción, octubre-noviembre 1957, $\mathrm{n}^{\circ}$ 273-274, p. 20-23.

TRAMOYERES BLASCO, Luis. Los artesonados de la antigua Casa Municipal de Valencia: Notas para la historia de la escultura decorativa en España. Valencia: Antonio López y Cía., 1917,. 44 p.

VICENT LERMA, Josept et al. La loza gótico-mudéjar en la ciudad de Valencia. Valencia: Ministerio de Cultura, Dirección General de Bellas Artes y Archivos, 1992, 185 p. ISBN 84-7483-834-7.

ZARAGOZA CATALÁN, Arturo. Iglesias de arcos diafragma y armadura de madera en la arquitectura medieval valenciana. Tesis Doctoral inédita. Valencia, Universidad Politécnica, julio 1990.

\section{NAVARRA}

Fernández-LAdReda AguAdé, Clara. La catedral de Pamplona. 2. Escalera del sobreclaustro. En Arte en Navarra. Pamplona: Diario de Navarra, 1994, p. 157.

\section{TOLEDO Y ZONA CENTRO}

\section{CiUdad Real}

Díez de BALdeón, Clementina. Almagro: Arquitectura y Sociedad. D.L. Toledo: Servicio de Publicaciones de la Junta de Comunidades de Castilla-La Mancha, 1993, 405 p. ISBN 84-7788-996-1. 


\section{CUENCA}

RIVERA GARRETAS, M. El castillo-fortaleza de Uclés. Datos histórico-arqueológicos. Revista Cuenca, 1980, $\mathrm{n}^{\circ} 17$, p. 35-49.

\section{GUADALAJARA}

Cuadrado Prieto, Miguel Angel y Crespo Cano, Ma ${ }^{a}$. Luz. Un alfar HispanoMusulmán en la plaza de la Antigua (Guadalajara). Wad-Al-Hayara, 1992, nº 19, p. 9-38.

GARCía López, Aurelio. Datos artísticos sobre el maestro de obras morisco, Acacio de Orejón (1519-d.1574). Wad-Al-Hayara, 1993, nº 20, p. 265-289.

\section{MADRID}

CONTRERAS, Juan de [marqués de LozoYA]. Nueva nota sobre la iglesia de Valdeolmos [sagrario mudéjar]. Investigación y Progreso, agosto 1940, nº 5, p. 143.

EsPaRraguera Calvo, Gloria. Las iglesias mudéjares madrileñas: estado de la cuestión. En Madrid del siglo IX al XI, Madrid, octubre-noviembre 1990. [s.1.]: Consejería de Cultura de la Comunidad de Madrid, [s.a.], p. 319-328.

LaVAdo Paradinas, Pedro José. Mudejarismo y neomudejarismo en Madrid. Boletín de la Asociación Española de Orientalistas, 1991, Año XXVII, p. 167-177.

- Restos mudéjares en la red viaria del Madrid medieval. En Caminos y Caminantes por las tierras del Madrid Medieval, Madrid, 1993. Edición de Cristina Segura Graiño. Madrid: Asociación Cultural AL-MUDAYNA, D.L. 1994, p. 347-359.

\section{TOLEDO}

AGUADO VILlaLBA, José. La cerámica hispano-musulmana de Toledo. Toletum, 1981$82, n^{\circ} 15$, p. $9-46$

- Reconstrucción y consolidación de azulejos mudéjares. Revista de Arqueología, 1986, nº 68, p. 44-50.

Amador de los Ríos, José. Púlpitos de estilo mudéjar en Toledo. Museo Español de Antigüedades, 1874, t. III, p. 325-347.

AMADOR DE LOS Ríos, Rodrigo. Brocales de pozo árabes y mudéjares. Museo Español de Antigüedades, 1874, t. III, p. 481-507.

- Toledo en los siglos XII y XIII, según los documentos muzárabigos. Revista de Archivos, Bibliotecas y Museos, mayo-junio 1904, t. X, $n^{\text {os }} 5$ y 6, p. 345-372.

ARANDA PÉREZ, F.J. Tipología de la portada civil toledana del gótico-mudéjar al plateresco. Beresit, 1988, 2, p. 37-64.

ARechaga, Carmen de. Antecedentes de la loza de cuerda seca en Toledo en el siglo XV. En Segundo Coloquio Internacional de Cerámica Medieval en el Mediterráneo Occidental, Toledo, 1981. Madrid: Ministerio de Cultura, Dirección General de Bellas Artes, 1986, p. 409-413. 
BARBE-COQUELIN DE LISLE, Geneviève. L'architecture mudejare au-dessus des trois religions. En Tolède XIIe-XIIIe. Musulmans, chrétiens et juifs: le savoir et la tolérance. Paris: Editions Autrement, 1991, p. 158-168.

Cabezas, A. Azulejería toledana del siglo XVI en la iglesia parroquial de Pezuela de las Torres. Archivo Español de Arte, 1991, n 256, p. 539-550.

Cabrera y Gallardo, Aurelio. La carpintería artística en Toledo [celosía de puerta mudéjar]. Toledo, 1917, n 76, p. 6-7.

Camps Cazorla, Emilio. Armario morisco, procedente de Toledo: Nota descriptiva. Madrid: Museo Arqueológico Nacional, 1931, 7 p.

Delgado VAlero, Clara. El mudéjar, una constante en Toledo entre los siglos XII y XV. En En AGUILAR, María Dolores et al. Mudéjar Iberoamericano: Una expresión cultural de dos mundos. I. Henares y R. López Guzmán (eds.). Granada: Servicio de Publicaciones de la Universidad de Granada, 1993, p. 79-107.

- El mudéjar toledano y su área de influencia. En El mudéjar iberoamericano: del Islam al Nuevo Mundo. Barcelona: Lunwerg Editores, 1995, p. 111-126.

HEYDECK, Juan Joseph. Las inscripciones hebreas de la sinagoga toledana de R. Semuel HaLevi. Ed. facsímil [de la obra Ilustración de la inscripción hebrea que se halla en la iglesia del Tránsito de la ciudad de Toledo. Madrid: imprenta Real, 1795 ]. Toledo: Editorial Fuensalida, 1978, XI + 63 p. ISBN 84-400-4243-4.

Lavado PARAdinas, Pedro José. La mezquita del Solarejo o de Tornerías en Toledo. En Actas Primer Congreso de Historia de Castilla-La Mancha, Ciudad Real, 16-20 diciembre, 1985. [s.1.]: Servicio de Publicaciones de la Junta de Comunidades de Castilla-La Mancha, 1988, t. I, p. 33-39.

Martínez Caviró, Balbina. El arte en los conventos de Toledo. En I Congreso Internacional del monacato femenino en España, Portugal y América 1492-1992. León: Universidad, Secretariado de publicaciones, D.L. 1993, t. II, p. 495-521.

Nuere Matauco, Enrique. Artesonados de Toledo. Toledo: Colegio Oficial de Aparejadores y Arquitectos Técnicos de Toledo, 1992, 256 p.

Pavon Maldonado, Basilio. La pila bautismal de Camarenilla (Toledo). Al-Qantara, 1983, vol. IV, fasc. 1 y 2, p. 381-383.

- Arte islámico y mudéjar en Toledo: la supuesta mezquita de las Santas Justa y Rufina y la Puerta del Sol. Al-Qantara, 1990, vol. 11, n 2, p. 509-526.

SAN ROMÁN Y FERNÁNDEZ, Francisco de Borja. La parroquia de San Andrés. Notas históricas. Toletum, 1981-82, nº 15, p. 207-219.

SÁNCHEZ MrGUel, Juan. Notable hallargo arqueológico [celosía de madera mudéjar]. Toledo: Revista de Arte, marzo 1922, n ${ }^{\circ}$ 181, p. 316.

Wilson Frontinghan, Alice. Ceramic baptismal fonts of Toledo province. En Actas del XIII Congreso Internacional de Historia del Arte: España entre el mediterráneo y el Atlántico, II, Granada, 1973. Granada: Universidad, Departamento de Historia del Arte, 1977, p. 100-108. 